\title{
Tip 2 Diyabet Hastalarında Diyabet Kontrolünü Zorlaştıran Faktörlerin İncelenmesi
}

\section{Investigating the Factors that Complicate Diabetes Control in Patients with Type 2 Diabetes}

\author{
Yavuz ÜREN ${ }^{\mathrm{a}}$, Elanur YILMAZ KARABULUTLU ${ }^{\mathrm{b}}$
}

\begin{abstract}
ÖZ Amaç: Araştırma Tip 2 diyabetli hastalarda diyabet kontrolünü zorlaştıran faktörlerin belirlenmesi amaciyla yapılmıştır. Gereç ve Yöntem: Tanımlayıcı olarak yapılan bu araştırma Van Bölge Eğitim ve Araştırma Hastanesi iç hastalıkları polikliniklerinde yapılmıştır. Araştırma Nisan-Ağustos 2015 tarihleri arasında muayene ve kontrol için başvuran ve araştırma kriterlerine uyan 150 Tip 2 Diyabetli hasta ile yürütülmüştür. Hastaların kişisel ve 1 bbi özelliklerinin belirlenmesi için "Hasta Bilgi Formu" ve diyabet kontrolünü zorlaştıran faktörlerin belirlenmesi için "Diyabet Bakım Profili" ölçeği kullanılmıştır. Verilerin analizi SPSS 23 paket programı ile yapılmıştır. Bulgular: Çalışmaya alınan hastasının yaş ortalaması $56.77 \pm 10.43$ yıl, Açlık Kan Şekeri ortalama $214.04 \pm 87.74$, HbA1c ortalamas1 $10.17 \pm 2.63$ ve Beden Kitle İndeksi $29.53 \pm 5.05$ bulunmuştur. Diyabetli hastaların diyabet yönetimini zorlaştıran faktörlerden en yüksek puan ortalaması negatif tutum (3.09 \pm 1.14$)$ alt boyutunda bulunmuştur. Hastaların diyabet yönetimini zorlaştıran faktörlerden en düşük puan ortalaması ise tedavi engellerinde (1.31 \pm 0.56$)$ bulunmuştur. Hastaların cinsiyet, yaş, eğitim, çalışma durumu, meslek, ekonomik durum gibi sosyodemografik özellikleri ile tanı süresi, kontrollerini düzenli yaptırma durumu, hastaneye yatış sayısı, tedavi şekli ve diyabete bağlı gelişen kronik komplikasyon varlığ gibi hastalığa ilişkin özelliklerin diyabet kontrolünü zorlaştıran faktörleri etkilediği görülmüştür $(\mathrm{p}<0.05)$. Sonuç: Tip 2 diyabet hastalarının metabolik kontrolünün iyi düzeyde olmadığı ve hastalığa karşı negatif tutumlarının yüksek olduğu belirlenmiştir. Hastaların bazı sosyodemografik ve hastalığa ilişkin özelliklerinin diyabet yönetimini zorlaştırdığı gözlenmiş̧ir. Hastaların diyabet yönetimi konusunda daha fazla desteklenmesi, olumsuz tutumlarının değiştirilmesi konusunda uygun girişimlerin yapılması, hastaların karşılaşsıkları kontrol problemlerinin ve etkilenen sosyal ve kişisel gereksinimlerinin belirlenmesi ve engellerin ortadan kaldırılmasına yönelik girişimlerin planlanması önerilmektedir.
\end{abstract}

Anahtar Kelimeler: Hemşirelik; diyabet bakım profili; tip 2 diyabetes mellitus.

ABSTRACT Aim: The study aimed to identify the factors that complicate the management of diabetes of Type 2 Diabetes Mellitus patients to disease processes. Material and Method: This descriptive study was conducted with 150 Type 2 Diabetes Mellitus patients who consulted Van Regional Training and Research Hospital Internal Medicine Polyclinics for medical exam and control between April-August 2015 and who fit the research criteria. In the study, "Patient Information Form" was used to identify patients' personal and medical characteristics and "Diabetes Care Profile" scala to determine the factors that complicated diabetes control. SPSS 23 statistics software program was used in data analysis. Results: Mean age for 150 participants was found to be $56.77 \pm 10.43$ years, mean Fasting Blood Glucose was 214.04 \pm 87.74 , HbAlc was $10.17 \pm 2.63$ and Body Mass Index was found to be $29.53 \pm 5.05$. Negative attitude mean score was identified to be the highest $(3.09 \pm 1.14)$ factor among salient factors that complicated diabetes management whereas barriers in treatment had the lowest mean score $(1.31 \pm 0.56)$ in diabetes management. It was determined that socio-demographic characteristics such as gender, age, education, status of employment and economic status and characteristics related to disease such as time of diagnosis, having regular check-ups, number of hospitalizations, type of treatment and existence of chronic complications related to diabetes have been found factors that complicate controlling diabetes ( $\mathrm{p}<0.05$ ). Conclusion: Metabolic control of patients with type 2 diabetes was not at a good level and their negative attitudes toward the disease were high. Some of the sociodemographic and diseaserelated characteristics of the patients made diabetes control difficult. It is proposed to further support the patients in diabetes management, to make appropriate attempts to change their negative attitudes, to plan the control problems faced by the patients and to identify the affected social and personal needs and to remove the barriers.

Keywords: Diabetes care profile; nursing; type 2 diabetes mellitus.

Geliş Tarihi/Received: 20-12-2017 / Kabul Tarihi/Accepted: 19-07-2018

a Öğr. Gör. Van Yüzüncü Yıl Üniversitesi, Sağlık Yüksekokulu, Van; ORCID: 0000-0002-1382-9200

b Prof. Dr. Atatürk Üniversitesi, Hemşirelik Fakültesi, Hemşirelik Bölümü, Erzurum, email: elanur@atauni.edu.tr, ORCID: 0000-0001-5798-853X

Sorumlu Yazar/Correspondence: Öğr. Gör. Yavuz ÜREN, Van Yüzüncü Yıll Üniversitesi, Sağlık Yüksekokulu, Van 


\section{Giriş}

Diyabet; pankreastan kan glukoz seviyesini düzenleyen insülin hormonunun yetersiz üretimi sonucu ortaya çıan, ya da üretilen insülinin vücutta kullanılamaması sonucu ortaya çıkan ciddi, kronik bir hastalıktır (1). Diyabetli hasta prevalans1 giderek artmakta ve tüm dünyada diyabetli hasta say1s1 2015 y1lı itibari ile 415 milyon iken 2040 yılında bu sayının artarak 642 milyona ulaşması öngörülmektedir (2). Dünya'da bir epidemi olarak nitelendirilen diyabet, insan sağlığını hem bireysel hem de toplumsal olarak olumsuz etkilemekte, ekonomik yük getirmekte ve yaşam kalitesini ciddi şekilde bozmaktadır (3). Diyabet takip ve tedavi ile birlikte kontrolü sağlanamadığında yıllar içinde çeşitli organların ve sistemlerin çalışması üzerine olumsuz etkiler bırakmaktadır. Bu nedenle diyabet yönetiminde; damarsal komplikasyonları önlemek, metabolik kontrolü normal düzeylerde tutmak, açlık kan şekeri değeri, tokluk kan şekeri değeri, glikolize hemoglobin, serum kolesterol düzeyleri, normal kan basıncı düzeyi ve trigliserit düzeyini sağlamak ve korumak, sigarayı bırakmak, ideal vücut ağırlığına ulaşmak hedeflenmelidir (4).

Diyabet uzun süreli bir hastalık olduğu için ömür boyu bakım ve yönetim gerektirir. Hastalar diyabet yönetiminde davranışsal seçim ve uygulamalara dayalı yaşam tarzı geliştirmek zorunda olduğundan dolayı diyabet bakımında merkezi konumdadır (5). Bunun için diyabetli bireyin hastalığının yönetiminde sorumluluk alabilmesi, tedavilerin faydaları ile ilgilenmesi ve majör tedavi engellerini algılayabilmesi, test sonuçlarını yorumlayabilmesi, etkili tıbbi beslenme tedavisini ve düzenli egzersiz programını sürdürebilmesi, uygun kan glukoz hedeflerini elde edebilmesi, hipoglisemiyi önleme ve tedavi etme konusunda etkili bireysel yönetimi gerçekleştirebilmesi sağlanmalıdır (6). Ancak diyabetliler hastalığın bireysel yönetimini sürdürürken bazı engeller ile karşılaşabilmektedir. Bunlar; kontrol problemleri (hiperglisemi ve hipoglisemi yaşama durumu), sosyal kişisel faktörler (sosyal çevre ile iletişim ve etkileşim), negatif tutum (hastalıktan korkma, endişelenme), tedavi engelleri (ilaçlarını uygulama) ve izleme engelleridir (AKȘ takibi ve sıklığında bozulma) (7). Hastaların karşılaştıkları zorluklar/engeller hastalık yönetimini aksatmaktadır (8). Diyabet yönetimi kötü olan hastalarda daha fazla hiperglisemi/hipoglisemi yaşanmakta ve nöropati ve retinopati gibi komplikasyonlar artmaktadır (9). Özellikle yoğun insülin tedavisisin oluşturduğu hipoglisemi korkusu, diyabete uyum ve metabolik kontrolü olumsuz etkilemektedir (10). Diyabet, hastaların sosyal ve kişisel yaşamlarını kısıtlayabilir ve özellikle diyet konusunda sinırlamalar yaşatabilir (11). Hastalığına karşı negatif tutum sergileyen hastaların tedavi süreçleri bozulabilir. Diyet uyumsuzluğu ve kontrollere gitmeme gibi oluşacak diyabet bakım engelleri kötü glisemik tablo oluşturarak hastaların yaşam kalitesini bozabilir (12). Diyabet hastalarının tedavilerinde yaşadıkları güçlüklerin hastaların yaşam kalitesini ve HbA1c düzeyini olumsuz etkilediği de gösterilmiştir (13). Bu yüzden diyabet hastalarının bakım süreçlerinde zorluklar/engellerin belirlenmesi ve bu zorluklar/engellere yönelik çözüm ve destekler üretilmesi diyabet yönetimi için oldukça önemlidir.

$\mathrm{Bu}$ araştırma Tip 2 Diyabet hastalarında kontrol problemleri, sosyal-kişisel faktörler, tıbbi engeller, negatif tutum, izleme engelleri ve egzersiz engelleri gibi diyabet kontrolünü zorlaştıran faktörleri belirlemek ve bu faktörlere sosyodemografik ve hastalığa ilişkin özelliklerin etkisini incelemek amacıyla yapılmıştır.

\section{Gereç ve Yöntem}

Araştırmanın verileri Nisan 2015 - Ağustos 2015 tarihleri arasında Van Bölge Eğitim ve Araştırma Hastanesi İç Hastalıkları Polikliniklerinde yürütülmüştür. Araştırmanın evrenini belirtilen tarihler arasında hastanenin İç Hastalıkları Polikliniklerine muayene ve kontrol amaciyla başvuran Tip 2 Diyabet tanısı almış hastalar oluşturmuştur. Nisan-Ağustos 2015 tarihleri arasında haftanın iki günü (Pazartesi ve Salı) veri toplanarak araştırmaya alınma kriterlerini karşılayan 150 kişi araştırma örneklemine alınmıştır. Araştırmaya alınma kriterleri; konuşma ve işitme kaybı olmama, psikiyatrik bir tanı almamış olma ve 18 yaş ve üzeri olmadır.

Verilerin toplanmasinda "Hasta Bilgi Formu" ve "Diyabet Bakım Profili" kullanıldı. Hasta Bilgi Formu diyabet hastalarının yaş, cinsiyet, eğitim durumu, çalışma durumu vb. gibi kişisel özellikleri, tedavi şekli, komplikasyon varlığı, hastaneye yatış sayısı ve düzenli olarak 
kontrolleri yaptırma durumu gibi hastalık özellikleri ve açlık kan şekeri, HbAlc, trigliserit, HDL kolesterol, LDL kolesterol gibi klinik parametreleri içeren sorulardan oluşmaktadır.

Araştırma kriterlerine uyan hastalar ile muayene sonrası polikliniklerde uygun bir odada görüşülerek araştırmanın amacı açıklanmıştır. Çalışmaya katılmayı kabul eden 150 hastaya veri toplama araçları içerisindeki sorular sorularak cevaplar uygulayıcı tarafından alınmıştır. Eğitim durumu, çalışma durumu vb. gibi kişisel özellikleri, tedavi şekli, komplikasyon varlığı, hastaneye yatış sayısı ve düzenli olarak kontrolleri yaptırma durumu gibi hastalık özelliklerini içeren soruların cevaplanmasında hastaların beyanları esas alınmıştır. Görüşmeler yaklaşık $25 \mathrm{dk}$. sürmüştür. Hastalar ile görüşüldüğü gün açlık kan şekeri, $\mathrm{HbA1c}$, trigliserit, HDL kolesterol, LDL kolesterol değerlerine hastane laboratuvar sonuçlarından ulaşılmıştır. Kilo, boy, kan basıncı, bel ve kalça çevresi araştırmacı tarafindan ölçülmüş ve beden kitle indeksi araştırmacı tarafından hesaplanmıştır.

Diyabet Bakım Profili: Michigan Diabetes Researchand Training Center'da görevli Anderson ve ark. (14) tarafindan 1989'da oluşturulmuş ve 1996 yılında aynı merkezde görevli olan Fitzgerald ve ark. (7) tarafindan yenilenmiştir. 1999 yılında H. Şeyda Özcan tarafindan Türkçe'ye çevrilerek geçerlik güvenilirlik çalışması yapılmıştır (11). Diyabet Bakım Profili'nde diyabet kontrolünü zorlaştıran faktörler; kontrol problemleri, sosyal-kişisel faktörler, negatif tutum, tıbbi engeller, izleme engelleri ve egzersiz engelleri olmak üzere 6 alt grup ve diyabet kontrolünü iyileştiren faktörleri kapsayan; pozitif tutum, öz-bakım yeterliliği, bakımın önemi, öz-bakıma uyum, diyete uyum, diyabet bilgisi, uzun dönem bakımının yararları, destek tutumları olmak üzere 8 alt gruptan oluşmaktadır. ${ }^{11} \mathrm{Bu}$ araştırmada Diyabet Bakım Profili içerisinde yer alan diyabet kontrolünü zorlaştıran faktörleri kapsayan 6 alt grup kullanıldı. Beşli likert tipi puanlama ile değerlendirilen ölçek maddeleri ile istenirse her alt boyut içindeki madde puanları toplanarak alt boyut madde sayısına bölünmesi ile 1'den 5'e kadar değişebilen alt boyut toplam puan ortalamaları hesaplanabilmektedir. Tüm ölçeğin total puanı hesaplanmamakta, sonuçlar alt boyut toplam puanları üzerinden değerlendirilmektedir (11). Alt grup puan ortalamalarına bakıldığında; "kontrol problemleri" için ortalamanın düşük olması hastanın hipoglisemi ve hiperglisemi gibi semptomları daha az yaşadığı, yüksek olması ise bu semptomlarla hastanın daha fazla karşılaştı̆g 1 söylenebilir. "Sosyal kişisel faktörler" ortalama puanının düşük olması hastaların diyabete bağlı gelişebilecek sosyal, ekonomik ve kişisel problemleri daha az yaşadığını, yüksek olması ise bu problemleri daha fazla yaşadığını gösterir. "Negatif tutum" ortalama puanının düşük olması hastaların diyabete bağlı gelişebilecek korku, mutsuzluk, üzüntü gibi deneyimleri daha az yaşadığını, yüksek olması ise bu deneyimlerin daha fazla yaşandığını gösterir. "Tedavi engelleri" ortalama puanının düşük olması hastaların OAD ve insülin kullanım dozlarına müdahale etmedikleri, yüksek olması ise OAD ve insülin kullanım dozlarına müdahale ettiklerini gösterir. "İzleme engelleri" ortalama puanının düşük olması hastaların kan şekeri izlemlerinin düzenli olduğunu, yüksek olması ise düzensizliği gösterir. "Egzersiz engelleri" ortalama puanının düşük olması hastaların egzersize engel sıklığının daha az olduğu, yüksek olması ise daha fazla engel yaşadıklarını gösterir. Yaptığımız çalışmada Cronbach's Alpha değerleri; kontrol problemleri için 0.84 , sosyal-kişisel faktörler için 0.91 , negatif tutum için 0.94 , tedavi engelleri için 0.88 , izleme engelleri için 0.93 ve egzersiz engelleri için 0.71 olduğu tespit edildi. Geçerlik ve güvenilirlik çalışmasının Cronbach's Alpha değerleri ile benzerlik gösteren çalışmamız bu yönüyle yüksek iç tutarlılık yansıtmaktadır.

İstatistiksel Analiz: Araştırmadan elde edilen verilerin analizi için SPSS 23 (Statistical Packages for the Social Sciences) istatistik paket programı kullanılmıştır. Hastaların kişisel ve hastalığa ait özelliklerinin analizinde yüzdelik testi kullanılmış, diyabet kontrolünü zorlaştıran faktörleri kapsayan 6 alt grubu puanların1 değerlendirmek için ise her alt grup aritmetik ortalama ve standart sapma değerleri hesaplanmıştır. Kişisel ve hastalık özelliklerinin diyabeti zorlaştıran faktörlere etkisini belirlemek için verilerin normal dağılım gösterip göstermediğine bakılarak iki kategorili grupları karşılaştırmada t-testi veya Mann Whitney U 
testi, ikiden fazla kategoriye sahip değişkenlerde Kruskal Wallis testi kullanılmıştır. Farklı grupları belirlemek için Duncan çoklu karşılaştırma testi kullanılmıştır. Yaş, tanı süresi ve metabolik kontrol değişkenleri ile diyabeti zorlaştıran faktörler arasındaki ilişkiyi belirlemede Pearson korelasyon katsayıları hesaplanmıştır. Hesaplamalarda istatistik anlamlılık düzeyi $\mathrm{p}<0.05$ olarak alınmıştır.

Gerekli izinler: Araştırma yapılmadan önce Atatürk Üniversitesi Sağlık Bilimleri Fakültesi Etik Kurulu Başkanlığından etik kurul onayı ve araştırmanın yapılacağı Van Kamu Hastaneler Birliği Genel Sekreterliği’nden Tez Çalışma İzni alınmıştır. Araştırma öncesinde hastalara araştırmanın amacı anlatılmış ve hastalardan "Gönüllülerin Rızasının Alınması Protokolü" çerçevesinde bilgilendirilmede bulunulmuştur. Araştırmaya katılım için gönüllü olan katılımcılardan yazılı onam alınarak uygulamaya başlanmıştır.

\section{Bulgular}

Hastaların yaş ortalaması $56.77 \pm 10.43$ yıl, \%38.7' si erkek, \%61.3' ü kadın, \%54.7' si eğitim almamış ve \%13.3' ü lise ve üzeri eğitim almıştır. Hastaların \%86.7' sinin çalışmadığ 1 belirlenmiş olup bunların \%62.0' si ev hanımı ve \%16' s1 emeklidir. Hastaların hastalığa ait özellikleri incelendiğinde; ortalama tanı süresinin $8.9 \pm 6.5$ yıl olduğu, hastaların $\% \quad 37.3^{\prime}$ ünün oral antidiyabetik tedavi aldığı ve \%55.3' ünün hastalığını başka hastalık muayenesinde öğrendiği, \%20' sinde diyabete bağl1 gelişen kronik komplikasyonların olduğu ve bu hastaların \%40'1nda böbrek yetmezliği geliştiği tespit edilmiştir. Hastaların \%44.7' sinin düzenli olarak kontrollerini yaptırdığ $1, \% 57.3$ ' ünün son bir yılda diyabet ya da komplikasyonları nedeniyle hastanede yattığı belirlenmiştir.

Hastaların AKŞ ortalaması 214.04 \pm 87.74 $\mathrm{mg} / \mathrm{dl}$ ve $\mathrm{HbA1c}$ ortalamas1 \%10.17 \pm 2.63 'dür. Ölçülen beden kitle indeksi ortalaması $29.53 \pm 5.05 \mathrm{~cm}$, sistolik kan basinc1 ortalamas $124.20 \pm 13.82 \mathrm{mmHg}$, diyastolik kan basinc1 ortalamas1 $76.40 \pm 10.82 \mathrm{mmHg}$ 'dır. Trigliserit ortalamas1 $191.71 \pm 122.05 \mathrm{mg} / \mathrm{dl}$, HDL kolesterol ortalamas1 $43.17 \pm 28.19 \mathrm{mg} / \mathrm{dl}$ ve LDL kolesterol ortalamas1 $121.60 \pm 51.06 \mathrm{mg} / \mathrm{dl}$ 'dır.
Hastaların ölçek alt boyutlarından aldıkları ortalama puanları incelendiğinde; negatif tutum alt boyutundan en yüksek ortalama puanı aldıkları

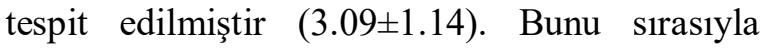
sosyal kişisel faktörler $(2.97 \pm 0.87)$, izleme engelleri (2.39 \pm 1.25$)$, egzersiz engelleri $(2.34 \pm 1.00)$, kontrol problemleri $(2.30 \pm 0.82)$ izlemektedir. En düşük ortalama puan ise tedavi engelleri alt boyutundan alınmıştır $(1.31 \pm 0.56)$ (Tablo 1).

Tablo 1. Hastaların ölçekten aldıkları ortalama puanları

\begin{tabular}{ll}
\hline $\begin{array}{l}\text { Diyabet Bakım Profili } \\
\text { (Diyabet kontrolünü zorlaştıran } \\
\text { faktörleri kapsayan alt boyutlar) }\end{array}$ & Ort. \pm SS \\
\hline Kontrol Problemleri & $2.30 \pm 0.83$ \\
\hline Sosyal Kişisel Faktörler & $2.97 \pm 0.87$ \\
\hline Negatif Tutum & $3.09 \pm 1.14$ \\
\hline Tedavi Engelleri & $1.31 \pm 0.56$ \\
\hline İzleme Engelleri & $2.39 \pm 1.26$ \\
\hline Egzersiz Engelleri & $2.34 \pm 1.00$ \\
\hline
\end{tabular}

Hastaların sosyodemografik özelliklerine göre diyabetin kontrolünü zorlaştıran faktörler Tablo 2'de verilmiştir. Hastaların cinsiyetlerinin sosyal ve kişisel faktörler ve negatif tutum ortalama puanlarında istatistiksel olarak anlamlı fark oluşturduğu belirlenmiştir. Kadın diyabet hastalarının erkek hastalara göre sosyal ve kişisel gereksinimlerinin $(p<0.05)$ ve hastalığa karş1 negatif tutumlarının $(\mathrm{p} \leq 0.01)$ anlamlı düzeyde yüksek olduğu görülmüştür. Hastaların eğitim durumlarına göre; sosyal ve kişisel faktörler, negatif tutum ve izleme engelleri ortalama puanlarında istatistiksel olarak anlamlı fark oluştuğu belirlenmiştir $(\mathrm{p}<0.05)$. Eğitim almamış hastaların $(3.05 \pm 0.82)$ ve ilkokul mezunu hastaların (3.16 \pm 3.16$)$ diğer eğitim düzeyine sahip olan hastalardan sosyal ve kişisel faktörler yönü ile daha fazla engele ve negatif tutuma sahip olduğu tespit edilmiştir. Eğitim almamış olan ve lise mezunu olan hastalarm daha fazla izleme engelleri ile karşılaştıkları belirlenmiştir $(\mathrm{p}<0.05)$ (Tablo 2). Çalışmayan hastaların sosyal ve kişisel gereksinimlerinin anlamlı düzeyde yüksek olduğu $(\mathrm{p} \leq 0.01)$, çalışan diyabet hastaların ise hastalığa yönelik negatif tutumlarının daha yüksek olduğu 
Tablo 2. Hastaların sosyodemografik özelliklerine göre ölçek alt boyutları ortalama puanlarının dağılımı

\begin{tabular}{|c|c|c|c|c|c|c|}
\hline & $\begin{array}{c}\text { Kontrol } \\
\text { Problemleri }\end{array}$ & $\begin{array}{c}\text { Sosyal ve Kişisel } \\
\text { Faktörler }\end{array}$ & $\begin{array}{l}\text { Negatif } \\
\text { Tutum }\end{array}$ & $\begin{array}{c}\text { Tedavi } \\
\text { Engelleri }\end{array}$ & $\begin{array}{c}\text { İzleme } \\
\text { Engelleri }\end{array}$ & $\begin{array}{l}\text { Egzersiz } \\
\text { Engelleri }\end{array}$ \\
\hline & Ort. \pm St.S & Ort. \pm St.S & Ort. \pm St.S & Ort. \pm St.S & Ort. \pm St.S & Ort. \pm St.S \\
\hline \multicolumn{7}{|l|}{ Cinsiyet } \\
\hline Erkek & $1.73 \pm 0.80$ & $2.80 \pm 0.96$ & $2.66 \pm 1.16$ & $1.40 \pm 0.62$ & $2.12 \pm 1.17$ & $2.15 \pm 0.94$ \\
\hline Kadın & $\begin{array}{c}1.87 \pm 0.81 \\
t=-1.06 \\
p=0.29\end{array}$ & $\begin{array}{c}3.08 \pm 0.80 \\
t=-1.95 \\
\mathbf{p}=\mathbf{0 . 0 2}\end{array}$ & $\begin{array}{c}3.36 \pm 1.05 \\
t=-3.78 \\
\mathbf{p}=\mathbf{0 . 0 1}\end{array}$ & $\begin{array}{c}1.26 \pm 0.53 \\
t=1.22 \\
p=0.22\end{array}$ & $\begin{array}{c}2.56 \pm 1.28 \\
t=-2.12 \\
p=0.52\end{array}$ & $\begin{array}{c}2.46 \pm 1.02 \\
t=-1.83 \\
p=0.58\end{array}$ \\
\hline \multicolumn{7}{|l|}{ Eğitim durumu } \\
\hline Eğitim almamıș & $1.77 \pm 0.82$ & $3.05 \pm 0.82$ & $3.18 \pm 1.19$ & $1.23 \pm 0.49$ & $2.67 \pm 1.29$ & $2.46 \pm 0.96$ \\
\hline İlkokul & $2.00 \pm 0.89$ & $3.16 \pm 0.83$ & $3.30 \pm 1.03$ & $1.44 \pm 0.65$ & $2.00 \pm 1.20$ & $2.32 \pm 0.98$ \\
\hline Ortaokul & $1.98 \pm 0.48$ & $2.95 \pm 0.87$ & $2.73 \pm 1.06$ & $1.23 \pm 0.49$ & $1.94 \pm 0.40$ & $2.52 \pm 1.34$ \\
\hline Lise & $1.62 \pm 0.60$ & $2.35 \pm 0.97$ & $2.57 \pm 1.10$ & $1.61 \pm 0.71$ & $2.39 \pm 1.21$ & $1.70 \pm 0.86$ \\
\hline \multirow{3}{*}{ Üniversite } & $1.35 \pm 0.62$ & $2.08 \pm 0.73$ & $2.19 \pm 0.72$ & 1.00 & $1.65 \pm 0.81$ & $2.00 \pm 0.79$ \\
\hline & $\mathrm{KW}=6.78$ & $\mathrm{KW}=13.80$ & $\mathrm{KW}=10.64$ & $\mathrm{KW}=7.98$ & $\mathrm{KW}=10.23$ & $\mathrm{KW}=7.69$ \\
\hline & $\mathrm{p}=0.148$ & $\begin{array}{c}\mathrm{p}=0.008 \\
(1,2>4,5) \\
(3>5)\end{array}$ & $\begin{array}{l}p=0.031 \\
(1,2>5)\end{array}$ & $\mathrm{p}=0.092$ & $\begin{array}{l}p=0.037 \\
(1,4>5)\end{array}$ & $\mathrm{p}=0.104$ \\
\hline \multicolumn{7}{|l|}{ Çalıșma durumu } \\
\hline Evet & $1.66 \pm 0.77$ & $2.34 \pm 0.89$ & $2.40 \pm 1.11$ & $1.25 \pm 0.66$ & $2.20 \pm 1.07$ & $2.05 \pm 1.07$ \\
\hline \multirow[t]{4}{*}{ Hayır } & $1.84 \pm 0.81$ & $3.06 \pm 0.83$ & $1.25 \pm 0.66$ & $1.32 \pm 0.55$ & $2.42 \pm 1.28$ & $2.38 \pm 0.98$ \\
\hline & MWU & $\mathrm{MWU}=712.5$ & MWU & MWU & MWU & MWU \\
\hline & $=1146.5$ & $\mathbf{P}=0.01$ & $=792.0$ & $=348.5$ & $=1234.0$ & $=1053.5$ \\
\hline & $\mathrm{p}=0.40$ & & $P=0.04$ & $\mathrm{p}=0.62$ & $\mathrm{p}=0.71$ & $\mathrm{p}=0.17$ \\
\hline \multicolumn{7}{|l|}{ Meslek } \\
\hline Ev hanımı & $1.86 \pm 0.2$ & $3.06 \pm 0.80$ & $3.33 \pm 1.07$ & $1.25 \pm 0.52$ & $2.56 \pm 1.27$ & $2.44 \pm 1.02$ \\
\hline İşçi & $2.01 \pm 0.49$ & $2.58 \pm 0.80$ & $2.30 \pm 1.38$ & $1.01 \pm 0.25$ & $2.57 \pm 1.40$ & $2.43 \pm 1.42$ \\
\hline Emekli & $1.57 \pm 0.7$ & $2.78 \pm 0.93$ & $2.92 \pm 1.10$ & $1.39 \pm 0.7$ & $1.73 \pm 0.84$ & $2.02 \pm 0.85$ \\
\hline Serbest meslek & $2.01 \pm 0.0$ & $3.40 \pm 0.75$ & $2.76 \pm 1.22$ & $1.48 \pm 0.9$ & $2.50 \pm 1.50$ & $2.45 \pm 0.89$ \\
\hline \multirow{4}{*}{ Memur } & $1.29 \pm 0.71$ & $2.04 \pm 0.90$ & $2.25 \pm 0.94$ & $2.00 \pm 0.91$ & $2.06 \pm 0.96$ & $1.94 \pm 0.87$ \\
\hline & $\mathrm{KW}=10.97$ & $K W=16.30$ & $\mathrm{KW}=13.01$ & $\mathrm{KW}=10.12$ & $\mathrm{KW}=7.81$ & $\mathrm{KW}=5.06$ \\
\hline & $\mathrm{p}=\mathbf{0 . 0 2 7}$ & $\mathrm{p}=\mathbf{0 . 0 0 3}$ & $p=0.011$ & $\mathrm{p}=\mathbf{0 . 0 3 8}$ & $\mathrm{p}=0.099$ & $\mathrm{p}=0.281$ \\
\hline & $(2,4>5)$ & $\begin{array}{c}(4>2) \\
(1,3,4>5)\end{array}$ & $(1>2,5)$ & $(5>1,2)$ & & \\
\hline \multicolumn{7}{|l|}{ Ekonomik durum } \\
\hline Muhtaç & $2.09 \pm 0.49$ & $3.58 \pm 0.89$ & $3.39 \pm 1.07$ & $1.51 \pm 0.71$ & $2.08 \pm 0.80$ & $2.62 \pm 0.76$ \\
\hline durumdayım & $2.06 \pm 1.10$ & $3.50 \pm 0.66$ & $3.24 \pm 0.89$ & $1.44 \pm 0.58$ & $2.12 \pm 1.30$ & $2.40 \pm 1.00$ \\
\hline Ancak geçiniyorum & $1.77 \pm 0.76$ & $2.95 \pm 0.84$ & $3.12 \pm 1.20$ & $1.30 \pm 0.58$ & $2.49 \pm 1.22$ & $2.36 \pm 0.98$ \\
\hline Orta derecede iyi & $1.74 \pm 0.79$ & $2.66 \pm 0.85$ & $2.91 \pm 1.15$ & $1.23 \pm 0.50$ & $2.38 \pm 1.37$ & $2.22 \pm 1.07$ \\
\hline İyi & $\begin{array}{c}\mathrm{KW}=3.16 \\
\mathrm{p}=0.37\end{array}$ & $\begin{array}{c}\mathrm{KW}=16.05 \\
\mathbf{p}=\mathbf{0 . 0 0 1} \\
(\mathbf{1}, \mathbf{2}>\mathbf{3}, \mathbf{4})\end{array}$ & $\begin{array}{c}\mathrm{KW}=2.92 \\
\mathrm{p}=0.40\end{array}$ & $\begin{array}{c}\mathrm{KW}=3.79 \\
\mathrm{p}=0.28\end{array}$ & $\begin{array}{c}\mathrm{KW}=1.64 \\
\mathrm{p}=0.65\end{array}$ & $\begin{array}{c}\mathrm{KW}=1.95 \\
\mathrm{p}=0.58\end{array}$ \\
\hline
\end{tabular}

$\mathrm{t}=$ Student $\mathrm{t}$ testi, $\mathrm{KW}=$ Kruskal-Wallis testi, MWU= Mann Whitney $\mathrm{U}$ testi

belirlenmiştir $(\mathrm{p}<0.05)$. Hastaların mesleklerine göre kontrol problemleri, sosyal kişisel faktörler, negatif tutum ve tedavi engelleri ortalama puanlarında istatistiksel olarak anlamlı farklılık tespit edilmiştir. Memur olan hastalar; serbest meslek sahibi ve işçi olanlara göre kontrol problemleri ile az karşılaşmakta $(\mathrm{p}<0.05)$ ve sosyal ve kişisel gereksinimleri daha az etkilenmektedir $(p<0.05)$. Ev hanımı olan hastaların daha fazla negatif tutuma sahip olduğu ve memur hastaların tedavi engellerini daha fazla algıladığ 1 belirlenmiştir $(\mathrm{p}<0.05)$. Hastaların ekonomik durumlarına göre sosyal kişisel faktörler ortalama puanlarında istatistiksel olarak 
Tablo 3. Hastaların hastalık özelliklerine göre ölçek alt boyutları ortalama puanlarının dağılımı

\begin{tabular}{|c|c|c|c|c|c|c|c|}
\hline & & $\begin{array}{c}\text { Kontrol } \\
\text { Problemleri }\end{array}$ & $\begin{array}{l}\text { Sosyal ve } \\
\text { Kişisel } \\
\text { Faktörler }\end{array}$ & $\begin{array}{l}\text { Negatif } \\
\text { Tutum }\end{array}$ & $\begin{array}{l}\text { Tedavi } \\
\text { Engelleri }\end{array}$ & $\begin{array}{l}\text { İzleme } \\
\text { Engelleri }\end{array}$ & $\begin{array}{l}\text { Egzersiz } \\
\text { Engelleri }\end{array}$ \\
\hline & & Ort. \pm St.S & Ort. \pm St.S & Ort. \pm St.S & Ort. \pm St.S & Ort. \pm St.S & Ort. \pm St.S \\
\hline Tedavi şekli & $\begin{array}{l}\text { OAD } \\
\text { İnsülin } \\
\text { Önceden OAD iken } \\
\text { şimdi insülin }\end{array}$ & $\begin{array}{c}1.54 \pm 0.95 \\
1.97 \pm 0.75 \\
1.98 \pm 0.64 \\
\mathrm{KW}=10.68 \\
\mathbf{p}=\mathbf{0 . 0 0 5} \\
(\mathbf{2}, \mathbf{3}>\mathbf{1})\end{array}$ & $\begin{array}{c}2.69 \pm 0.76 \\
2.72 \pm 0.81 \\
3.28 \pm 0.88 \\
\mathrm{KW}=18.19 \\
\mathbf{p}=\mathbf{0 . 0 0 1} \\
\mathbf{( 3 > 1 , 2 )}\end{array}$ & $\begin{array}{c}3.00 \pm 1.08 \\
3.00 \pm 1.18 \\
3.18 \pm 1.18 \\
\mathrm{KW}=1.43 \\
\mathrm{p}=0.49\end{array}$ & $\begin{array}{c}1.51 \pm 0.63 \\
1.24 \pm 0.52 \\
\text { MWU } \\
=507.0 \\
\mathbf{p}=\mathbf{0 . 0 0 1}\end{array}$ & $\begin{array}{c}2.65 \pm 1.24 \\
2.03 \pm 1.20 \\
2.30 \pm 1.23 \\
\mathrm{KW}=5.91 \\
\mathrm{p}=0.052\end{array}$ & $\begin{array}{c}2.22 \pm 0.93 \\
2.17 \pm 0.98 \\
2.50 \pm 1.05 \\
\mathrm{KW}=3.49 \\
\mathrm{p}=0.17\end{array}$ \\
\hline $\begin{array}{l}\text { Kronik } \\
\text { komplikasyon } \\
\text { varlığ1 }\end{array}$ & $\begin{array}{l}\text { Evet } \\
\text { Hayır }\end{array}$ & $\begin{array}{c}1.91 \pm 0.72 \\
1.79 \pm 0.83 \\
t=0.71 \\
p=0.48\end{array}$ & $\begin{array}{c}3.18 \pm 0.99 \\
2.92 \pm 0.84 \\
t=1.50 \\
p=0.13\end{array}$ & $\begin{array}{c}3.13 \pm 1.08 \\
3.08 \pm 1.16 \\
t=0.21 \\
p=0.84\end{array}$ & $\begin{array}{c}1.41 \pm 0.72 \\
1.27 \pm 0.49 \\
\mathrm{t}=0.89 \\
\mathrm{p}=0.38 \\
\end{array}$ & $\begin{array}{c}2.55 \pm 1.38 \\
2.35 \pm 1.22 \\
t=0.81 \\
p=0.42\end{array}$ & $\begin{array}{c}2.67 \pm 0.84 \\
2.26 \pm 1.02 \\
t=2.26 \\
\mathbf{p}=\mathbf{0 . 0 3}\end{array}$ \\
\hline $\begin{array}{ll}\text { Son bir } & \text { y1lda } \\
\text { hastaneye } & \text { yatış } \\
\text { sayısı } & \end{array}$ & $\begin{array}{l}\text { Yatmadım } \\
1 \mathrm{kez} \\
2 \mathrm{kez} \\
3 \mathrm{kez} \text { ve üzeri }\end{array}$ & $\begin{array}{c}1.65 \pm 0.76 \\
1.76 \pm 0.77 \\
2.06 \pm 1.02 \\
2.37 \pm 0.63 \\
\mathrm{KW}=12.68 \\
\mathbf{p}=\mathbf{0 . 0 0 5} \\
\mathbf{( 4 > 1 , 2 )} \\
\end{array}$ & $\begin{array}{c}2.71 \pm 0.83 \\
3.02 \pm 0.90 \\
3.20 \pm 0.66 \\
3.59 \pm 0.75 \\
K W=15.65 \\
\mathbf{p}=\mathbf{0 . 0 0 1} \\
(\mathbf{4}>\mathbf{1 , 2 )} \\
\end{array}$ & $\begin{array}{c}2.92 \pm 1.21 \\
3.18 \pm 1.11 \\
3.17 \pm 1.08 \\
3.34 \pm 1.02 \\
\mathrm{KW}=2.43 \\
\mathrm{p}=0.49\end{array}$ & $\begin{array}{c}1.26 \pm 0.59 \\
1.23 \pm 0.45 \\
1.66 \pm 0.70 \\
1.44 \pm 0.64 \\
K W=8.60 \\
p=0.13\end{array}$ & $\begin{array}{c}2.46 \pm 1.35 \\
2.41 \pm 1.31 \\
2.43 \pm 0.96 \\
2.01 \pm 0.89 \\
\mathrm{KW}=1.10 \\
\mathrm{p}=0.77\end{array}$ & $\begin{array}{c}2.42 \pm 0.90 \\
2.20 \pm 1.20 \\
2.16 \pm 0.75 \\
2.65 \pm 0.73 \\
\mathrm{KW}=5.30 \\
\mathrm{p}=0.15\end{array}$ \\
\hline $\begin{array}{l}\text { Kontrolleri } \\
\text { düzenli } \\
\text { yaptırma } \\
\text { durumu }\end{array}$ & $\begin{array}{l}\text { Evet } \\
\text { Hayır }\end{array}$ & $\begin{array}{c}1.82 \pm 0.72 \\
1.81 \pm 0.88 \\
t=0.51 \\
p=0.96\end{array}$ & $\begin{array}{c}2.97 \pm 0.98 \\
2.97 \pm 0.78 \\
t=-0.003 \\
p=0.99\end{array}$ & $\begin{array}{c}2.93 \pm 1.22 \\
3.21 \pm 1.07 \\
t=-1.51 \\
p=0.13\end{array}$ & $\begin{array}{c}1.31 \pm 0.53 \\
1.31 \pm 0.59 \\
t=-0.55 \\
p=0.96\end{array}$ & $\begin{array}{c}2.09 \pm 1.17 \\
2.62 \pm 1.28 \\
\mathrm{t}=-2.60 \\
\mathbf{p}=\mathbf{0 . 0 1}\end{array}$ & $\begin{array}{c}2.30 \pm 0.96 \\
2.37 \pm 1.03 \\
t=-0.40 \\
p=0.68\end{array}$ \\
\hline
\end{tabular}

$\mathrm{t}=$ Student $\mathrm{t}$ testi, KW= Kruskal-Wallis testi, MWU= Mann Whitney U testi

anlamlı fark oluşturduğu belirlenmiştir $(\mathrm{p}<0.01)$. Ekonomik olarak kendisini muhtaç durumda algilayan hastaların $(3.58 \pm 0.89)$ sosyal ve kişisel gereksinimlerinin daha fazla $(3.58 \pm 0.89)$ etkilendiği belirlenmiştir (Tablo 2).

Diyabet hastalarının hastalığa ilişkin özelliklerine göre diyabet kontrolünü zorlaştıran faktörler incelendiğinde; hastaların tedavi şekillerine göre kontrol problemleri, sosyal kişisel faktörler ve tedavi engelleri ortalama puanlarında istatistiksel olarak anlamlı farklılık oluştuğu belirlendi. Tedavi şekli oral antidiyabetik olan hastaların kontrol problemleri ile daha az karşılaştıkları $(p<0.05)$, sosyal ve kişisel gereksinimlerinin daha az etkilendiği $(\mathrm{p}<0.01)$ ve insülin ile tedavi gören hastaların ise tedavi engellerinin yüksek olduğu $\quad(p<0.01)$ belirlenmiştir. Diyabete bağlı gelişen kronik komplikasyona sahip olma durumuna göre egzersiz engeli ortalama puanlarında $(\mathrm{p}<0.05)$,

komplikasyonlar veya diyabet nedeniyle son bir yılda hastaneye yatış sayısına göre ise kontrol problemleri $(\mathrm{p}<0.05)$ ve sosyal kişisel faktörler $(\mathrm{p}<0.01)$ ortalama puanlarına istatistiksel olarak farklılık oluştuğu belirlenmiştir. Kontrollerini düzenli yaptırma durumuna göre izleme engellerinde fark olduğu tespit edilmiştir $(\mathrm{p}<0.01)$ (Tablo 3). Hastaların yaş, tanı süresi ve metabolik kontrol değişkenleri ve ölçek alt grup ortalamaları arasındaki ilişki Tablo 4' te gösterilmiştir. Hastaların yaşları ile negatif tutum alt boyut ortalama puanları arasında pozitif yönde ilişki olduğu belirlenmiştir $(p<0.05)$. Tanı süresi ile kontrol problemleri ve sosyal kişisel faktör arasında pozitif yönde ilişki olduğu bulunmuştur $(p<0.05)$. HbAlc seviyesi ile izleme engelleri $(p<0.01)$, BKİ ile egzersiz engelleri $(p<0.01)$, HDL kolesterol seviyesi ile kontrol problemleri $(\mathrm{p}<0.01)$ ve LDL kolesterol seviyesi ile negatif tutum arasında pozitif yönde güçlü bir ilişki bulunmuştur $(\mathrm{p}<0.01)$ (Tablo 4).

\section{Tartışma}

$\mathrm{Bu}$ araştırmada hastaların AKŞ ve HbAlc değerleri yüksek ve beden kitle indeksi ortalamas1 hastaların obezite sınırında olduğunu göstermektedir. Trigliserit değeri ortalamas1 hedef trigliserid değerinden yüksek, HDL kolesterol 
değeri ortalaması hedef HDL değerinden düşük ve LDL kolesterol değeri ise hedef LDL değerinden yüksek bulunmuştur. Amerika Diyabet Birliği (15), ve Sağlık Bakanlığg Türkiye Diyabet Programı (3) güncel kaynaklarında belirtilen hedef değerler incelendiğinde hastaların metabolik kontrolünün kötü olduğu ve hastalık yönetiminde daha fazla yardıma gereksinim duydukları görülmektedir.

Diyabetli hastaların diyabet yönetimini zorlaştıran faktörlerden negatif tutum puan ortalamasının en yüksek olduğu belirlenmiştir (Tablo 1). Bu veriler hastaların diyabete karşı korku, ümitsizlik, endişe gibi negatif tutumlarının olduğunu göstermekte ve literatürde de bu durumun yaygın olduğu görülmektedir $(11,16$ 20). Benzer olarak ülkemizde yapilan çalışmalarda diyabet hastalarının hastalığa karşı negatif tutumlarının yüksek olduğu bazı araştırmalarda ortaya konmuştur $(11,16,17)$. Hastaların diyabete uyumunu engelleyen ve diyabet yönetimini zorlaştıran faktörlerden en düşük puan ortalaması ise tedavi engellerinde bulunmuştur. Tedavi engelleri ilaç tedavilerini bilme, günlük aktivitelere uygun insülin dozunu ayarlayabilme ve uygulayabilme ile ilgili engelleri içermektedir. Konu ile ilgili yapılan diğer çalışmalarda da diyabetlilerin tedavi engellerini düşük düzeyde algıladıkları gösterilmiştir $(11,16,21,22)$. Diyabet hastaları kan şekeri test sonucuna göre insülin dozunu ayarlayabilmeli, aşırı fiziksel egzersiz durumunda insülin dozunu azaltabilmeli, enfeksiyon durumunda insülin dozunu arttırabilmelidir (4). $\mathrm{Bu}$ yönüyle düşünüldüğünde araştırma sonucu hastaların hastalığın kontrolünde ilaçları ve insülin dozu ayarlama ve uygulama konusunda engel algısının düşük olduğunu göstermektedir. Hastaların tedavi engellerini diyabet kontrolünü zorlaştıran önemli bir etken olarak görmedikleri düşünülmektedir.

Hastaların sosyodemografik özelliklerine göre diyabetin kontrolünü zorlaştıran faktörler incelendiğinde; cinsiyetin hastaların sosyal ve kişisel gereksinimlerini ve negatif tutumlarını etkilediği tespit edilmiştir. Çalışmaya katılan kadın hastaların erkeklere göre sosyal ve kişisel gereksinimlerinin daha çok etkilendiği $(p<0.05)$ ve daha fazla negatif tutuma $(\mathrm{p}<0.01)$ sahip olduğu görülmektedir (Tablo 2). Orhan ve Karabacak'ın çalışmasında da kadınların erkeklere göre hastalık nedeni ile iş, sosyal ve eğlence aktivitelerinin daha olumsuz etkilendiği belirtilmiştir (23). Toplum içerisinde kadına yüklenen rollerden dolayı aile yaşamındaki sorumlulukları ağırdır (24). Diyabetlilerin hastalık tutumları ilgili araştırmalar incelendiğinde ise farklı sonuçların ortaya çıtığ 1 görülmektedir. Kartal ve ark. Türk toplumunda yaptıkları çalışmalarında kadın diyabet hastalarının erkeklerden daha kötü tutuma sahip olduğunu (25), bu çalışma bulgusunun aksine Fatema ve ark. Bangladesh'te yaptıkları bir araştırmada ise diyabetli kadınların erkeklere göre daha iyi diyabet tutumuna sahip olduğunu belirtmişlerdir (26). Bu sonuçlar cinsiyetin hastalık tutumu üzerindeki etkisinin kültürel farklılardan kaynaklandığını düşündürmektedir. Eğitim düzeyi arttıkça sosyal ve kişisel gereksinimlerin daha az etkilendiği ve negatif tutumun ve izleme engellerinin azaldığ 1 görülmektedir $(\mathrm{p}<0.05)$. Haddad ve ark. Malezya'da yaptıkları çalışmada benzer bulgular elde etmiş, diyabet hastalığının eğitim düzeyi arttıkça sosyal ve kişisel gereksinimleri daha az etkilediğini görmüştür (20). Ülkemizde yapılan diğer bir çalışmada da eğitim düzeyi yüksek olan hastaların daha pozitif tutum sergiledikleri gösterilmiştir (25). Çalışan hastaların negatif tutumlarının çalışmayan hastalardan anlamlı düzeyde yüksek olduğu saptandı $(\mathrm{p}<0.05)$. İş hayatının bazı çalışanlar için stres kaynağı olması ve hastalığa bağlı oluşan stresi arttırdığ 1 düşünülebilir. Çalışan hastaların sosyal ve kişisel gereksinimlerinin daha az etkilendiği saptand $(p<0.01)$. Yapılan bir çalışmada çalışan hastaların hastalık bakım yönetimlerinin çalışmayan hastalardan anlamlı seviyede düşük olduğu gösterilmiştir (27). Memur olan hastalar diğer meslek gruplarına göre hipoglisemi, hiperglisemi gibi kontrol problemleri ile az karşılaşmakta, sosyal-kişisel gereksinimleri daha az etkilenmekte ve tedavi engelleri ile daha fazla karşılaşmaktadır. $\mathrm{Bu}$ sonuçta memur olan hastaların rutin yaşam tarzlarından dolayı yemek saatlerinin daha düzenli olması ve buna bağlı olarak ta ilaç alımlarındaki düzenin etkisi olabileceği düşünülmektedir. Çalışmada ev hanımı olan hastaların hastalığa karşı daha fazla negatif tutuma sahip olduğu görülmektedir. Araştırmanın yapıldığ 1 Van ilinde çoğunluğu ev hanımı olan yetişkin kadın nüfusunun eğitim 
seviyesinin düşük olmasının bu sonucu etkilediği düşünülmektedir.

Tablo 4. Hastaların ölçek alt boyutlarından aldıkları ortalama puanları ile yaş, tanı süresi ve metabolik kontrol değişkenleri arasındaki ilişki

\begin{tabular}{|c|c|c|c|c|c|c|}
\hline & $\begin{array}{c}\text { Kontrol } \\
\text { Problemleri } \\
\end{array}$ & $\begin{array}{c}\text { Sosyal ve Kişisel } \\
\text { Faktörler }\end{array}$ & $\begin{array}{c}\text { Negatif } \\
\text { Tutum }\end{array}$ & $\begin{array}{c}\text { Tedavi } \\
\text { Engelleri }\end{array}$ & $\begin{array}{l}\text { İzleme } \\
\text { Engelleri }\end{array}$ & $\begin{array}{l}\text { Egzersiz } \\
\text { Engelleri }\end{array}$ \\
\hline Yaş & $\begin{array}{l}r=0.04 \\
p=0.60\end{array}$ & $\begin{array}{l}r=0.12 \\
p=0.14\end{array}$ & $\begin{array}{l}r=0.18 \\
\mathbf{p}=\mathbf{0 . 0 3}\end{array}$ & $\begin{array}{l}r=0.02 \\
p=0.85\end{array}$ & $\begin{array}{l}r=-0.11 \\
p=0.19\end{array}$ & $\begin{array}{l}r=0.13 \\
p=0.12\end{array}$ \\
\hline Tanı Süresi & $\begin{array}{l}r=0.19 \\
\mathbf{p}=\mathbf{0 . 0 3}\end{array}$ & $\begin{aligned} r & =0.16 \\
p & =\mathbf{0 . 0 4 8}\end{aligned}$ & $\begin{array}{l}r=0.03 \\
p=0.76\end{array}$ & $\begin{array}{l}r=0.02 \\
p=0.87\end{array}$ & $\begin{array}{l}r=-0.12 \\
p=0.15\end{array}$ & $\begin{array}{l}r=0.03 \\
p=0.70\end{array}$ \\
\hline Açlık Kan Şekeri & $\begin{array}{l}r=0.04 \\
p=0.64\end{array}$ & $\begin{array}{l}r=0.11 \\
p=0.17\end{array}$ & $\begin{array}{l}r=0.07 \\
p=0.38\end{array}$ & $\begin{array}{l}\mathrm{r}=-0.20 \\
\mathrm{p}=0.054\end{array}$ & $\begin{array}{l}r=0.15 \\
p=0.07\end{array}$ & $\begin{array}{l}r=0.06 \\
p=0.48\end{array}$ \\
\hline HbA1c & $\begin{array}{l}r=0.13 \\
p=0.11\end{array}$ & $\begin{array}{l}r=0.11 \\
p=0.17\end{array}$ & $\begin{array}{l}r=0.03 \\
p=0.73\end{array}$ & $\begin{array}{l}r=-0.02 \\
p=0.85\end{array}$ & $\begin{aligned} r & =0.30 \\
\mathbf{p} & =\mathbf{0 . 0 0 1}\end{aligned}$ & $\begin{array}{l}r=0.05 \\
p=0.54\end{array}$ \\
\hline Beden Kitle İndeksi & $\begin{array}{l}r=0.06 \\
p=0.50\end{array}$ & $\begin{array}{l}r=-0.01 \\
p=0.91\end{array}$ & $\begin{array}{l}r=0.03 \\
p=0.68\end{array}$ & $\begin{array}{l}r=-0.05 \\
p=0.62\end{array}$ & $\begin{array}{l}r=0.05 \\
p=0.49\end{array}$ & $\begin{aligned} r & =0.23 \\
\mathbf{p} & =\mathbf{0 . 0 0 4}\end{aligned}$ \\
\hline Sistolik Kan Basıncı & $\begin{array}{l}r=0.06 \\
p=0.45\end{array}$ & $\begin{array}{l}r=0.06 \\
p=0.46\end{array}$ & $\begin{array}{l}r=0.01 \\
p=0.93\end{array}$ & $\begin{array}{l}r=0.14 \\
p=0.18\end{array}$ & $\begin{array}{l}r=0.13 \\
p=0.11\end{array}$ & $\begin{array}{c}r=0.16 \\
p=0.053\end{array}$ \\
\hline Diyastolik Kan Basıncı & $\begin{array}{l}r=0.03 \\
p=0.75\end{array}$ & $\begin{array}{l}\mathrm{r}=-0.01 \\
\mathrm{p}=0.94\end{array}$ & $\begin{array}{l}r=0.01 \\
p=0.92\end{array}$ & $\begin{array}{l}\mathrm{r}=0.06 \\
\mathrm{p}=0.58\end{array}$ & $\begin{array}{l}r=0.06 \\
p=0.46\end{array}$ & $\begin{array}{l}r=0.01 \\
p=0.85\end{array}$ \\
\hline Trigliserit & $\begin{array}{l}r=-0.03 \\
p=0.67\end{array}$ & $\begin{array}{l}r=0.10 \\
p=0.22\end{array}$ & $\begin{array}{l}r=0.01 \\
p=0.92\end{array}$ & $\begin{array}{l}r=-0.02 \\
p=0.86\end{array}$ & $\begin{array}{l}r=-0.01 \\
p=0.99\end{array}$ & $\begin{array}{l}r=0.02 \\
p=0.76\end{array}$ \\
\hline HDL kolesterol & $\begin{aligned} r & =0.22 \\
\mathbf{p} & =\mathbf{0 . 0 0 8}\end{aligned}$ & $\begin{array}{l}r=0.07 \\
p=0.39\end{array}$ & $\begin{array}{l}r=0.03 \\
p=0.69\end{array}$ & $\begin{array}{l}r=-0.09 \\
p=0.41\end{array}$ & $\begin{array}{l}r=-0.06 \\
p=0.43\end{array}$ & $\begin{array}{l}r=0.03 \\
p=0.66\end{array}$ \\
\hline LDL kolesterol & $\begin{array}{l}r=0.01 \\
p=0.85\end{array}$ & $\begin{array}{l}r=0.15 \\
p=0.06\end{array}$ & $\begin{aligned} r & =0.28 \\
\mathbf{p} & =\mathbf{0 . 0 0 1}\end{aligned}$ & $\begin{array}{l}r=0.03 \\
p=0.74\end{array}$ & $\begin{array}{l}r=-0.05 \\
p=0.52\end{array}$ & $\begin{array}{l}r=0.11 \\
p=0.19\end{array}$ \\
\hline
\end{tabular}

Pearson korelasyon analizi

Nitekim 2013 y1lı Türkiye İstatistik Kurumu verilerine göre okuma yazma bilmeyen kadınların oranı Türkiye genelinde yaklaşık \% 6 iken Van ilinde yaklaşık \% 13 olduğu bilinmektedir (28). Hastaların ekonomik durumu kötüleştikçe sosyal ve kişisel gereksinimlerinin daha fazla etkilendiği bulundu ( $\mathrm{p}<0.001)$. Haddad ve ark. yaptıkları çalışmada benzer sonuca ulaşmışlardır (20). Ekonomik durumun kötü olması bireylerin sosyal ve kişisel gereksinimlerini karşılamak için yeterli para ayıramamalarına neden olabilir. Nitekim Amerika'da düşük gelirli ve sigortasız diyabet hastalarının çoğunlukta olduğu bir bölgede yapılan çalışmada diyabet hastalarının başarılı hastalık yönetimlerinin zor olduğu belirtilmiştir (29).

Hastaların hastalığa ilişkin özelliklerine göre diyabet kontrolünü zorlaştıran faktörler incelendiğinde; uygulanan tedavi şekli önceden OAD iken şimdi insülin olan hastaların sadece insülin yada $\mathrm{OAD}$ kullanan hastalara göre daha fazla kontrol problemleri ile karşılaştıkları $(p<0.05)$ ve sosyal ve kişisel gereksinimlerinin daha fazla etkilendiği tespit edilmiştir $(\mathrm{p}<0.01)$. $\mathrm{Bu}$ bulgu Li ve ark. çalışma sonuçları ile benzerlik göstermektedir (22). Ayrıca insülin ile tedavi edilen diyabetlilerin tedavi engelleri puan ortalamalarının önceden OAD kullanırken şimdi insülin kullanan hastalardan daha yüksek olduğu tespit edilmiştir. Bu sonuç insülin ile tedavi edilen diyabetlilerin ilaç tedavilerini bilme, günlük aktivitelere uygun insülin dozunu ayarlayabilme ve uygulayabilme ile ilgili engelleri daha fazla algıladıklarını göstermektedir. Nitekim insülin tedavisine başlanan Tip 2 diyabetlilerin tedavinin ilk y1llarında glisemik kontrolünün anlamlı derecede iyileştiği fakat hipoglisemi deneyimlerinin ciddi derecede ortaya çıktığı gösterilmiştir (30). Diyabete bağlı kronik komplikasyon gelişen hastaların daha fazla egzersiz engeli yaşadığı belirlenmiştir $(\mathrm{p}<0.05)$. Fiziksel aktivite kronik komplikasyon gelişimi riskini azaltmaktadır (25). $\mathrm{Bu}$ nedenle fiziksel egzersiz engellerinin ortadan kaldırılması diyabet kontrolünde yarar sağlayacak önemli bir faktördür. Diyabet veya komplikasyonları nedeniyle hastaneye yatış sayısı artıça hastaların daha fazla kontrol problemleri ile karşılaştığ 1 görülmüştür $(\mathrm{p}<0.01)$. Bu bulgu hastalık veya komplikasyonları nedeniyle daha çok hastaneye yatan hastaların daha çok hipoglisemi/hiperglisemi yaşadığını ve bunlarla ilişkili semptomları daha fazla hissettiğini 
göstermektedir. Aynı şekilde yatış sıklığı artıkça hastaların sosyal ve kişisel gereksinimlerinin de daha fazla etkilendiği bulunmuştur $(\mathrm{p}<0.01)$. Yavuz ve ark. yaptıkları çalışma ile hipergliseminin hastanede yatış süresinde uzamaya neden olan bir faktör olduğunu göstermişlerdir (31). Hastanede yatış sosyal yönden kişiyi kısıtlayan ve iş, aile ve sosyal çevreden uzaklaştıran önemli bir etkendir. Hastaneye yatış sayısı arttıkça kişinin sosyal çevresinden ayrı kalması, yapmak istediklerini yapamaması ve para kazanma ile ilgili sorunlar yaşaması muhtemeldir.

Yaş arttıkça negatif tutumun arttığı tespit edilmiştir $(p<0.05)$. Mumu ve ark. yaş ile birlikte diyabete karşı farkındalığın artmasına rağmen negatif tutumun arttığını göstermiştir (32). Mansyur ve ark.'nın çalışmasında yaş arttıkça diyete ve diyabet bakımına uyumun azaldığ gösterilmiştir (33). Yaşlanmayla artan kronik hastalıklar, kișisel yetersizliklerin artması ve günlük yaşam aktivitelerindeki bağımlılık, yaşam kalitesini azaltarak kronik hastalığa sahip yaşliların olumsuz tutum sergilemelerine neden olabilmektedir $(34,35)$. Tanı süresi arttıkça hastaların kontrol problemleri ile daha fazla karşılaştıkları bulunmuştur $(\mathrm{p}<0.05) . \mathrm{Bu}$ sonuç tanı süresinin artması ile birlikte hastaların daha çok hipoglisemi/hiperglisemi yaşadığını ve bunlarla ilişkili semptomları daha fazla hissettiğini göstermektedir. Yapılan çalışmalarda tanı süresi ile kötü metabolik kontrol arasında pozitif ilişki tespit edilmiştir (36,37). Ayrıca tanı süresi arttıça diyabetlilerin sosyal ve kişisel gereksinimleri daha fazla engellenmektedir. Konu ile ilgili başka bir çalışmada da bu araştırma bulgusuna benzer olarak yaş artıkça günlük yaşam iş, sosyal ve eğlence aktivitelerinin engellendiği algısının arttığı tespit edilmiştir (23).

Hastaların metabolik kontrol değişkenleri ile diyabet kontrolünü zorlaştıran faktörler arasındaki ilişki incelendiğinde; hastaların izleme engelleri arttıkça HbAlc değerleri artmaktadır. İzleme engelleri hastanın kan şekeri takibi yapması/yaptırmasını engelleyen faktörler olarak değerlendirilmektedir. Diyabetli hastalar kan şekeri ölçümlerini kendileri yaparak kan şekeri seviyesini hedef düzeylerde tutabilir. Kan şekeri ölçümünü kendi yapabilen hastaların komplikasyon oranlarının daha düşük olduğu belirlenmiştir (38). Bu nedenle hastaların kendi kendine izlem konusunda eğitilmesinin gerekliliği ortaya çıkmaktadır. BKİ değeri ile egzersiz engelleri arasında pozitif yönlü korelasyon bulunmuştur $(p<0.01)$. Benzer şekilde Kara ve Çınar'ın çalışmasında da egzersiz engelleri ile BKI arasında pozitif yönlü ilişki olduğu belirlenmiştir (16). Bu çalışmada LDL kolesterol değeri ile negatif tutum arasında pozitif ilişki olduğu görülmektedir $(p<0.01)$. Benzer şekilde olumsuz tutuma sahip diyabet hastalarının metabolik kontrol düzeylerinin daha kötü olduğu, $\mathrm{HbAlc}$ ve kan basınçlarının da daha yüksek olduğu gösterilmiştir (11).

\section{Sonuç}

Çalışmamızda diyabet yönetimini zorlaştıran en önemli faktörün hastaların negatif tutumu olduğu belirlenmiştir. Kadın hastaların, okula gitmeyenlerin, çalışanların, ev hanımı olanların daha fazla negatif tutum gösterdikleri görülmüştür.

İşçi ve serbest meslek sahiplerinin, son bir y1lda 3 ya da daha fazla hastaneye yatanların ve önceden oral antidiyabetik kullanırken şimdi insülin tedavisine geçen hastaların daha fazla kontrol problemi yaşadığı, kadın hastaların, okula gitmeyenlerin, çalışmayanların, ev hanımı ve serbest meslek sahiplerinin, ekonomik olarak kendini muhtaç olarak algilayanların, son bir yilda 3 ya da daha fazla hastaneye yatanların ve önceden oral antidiyabetik kullanırken şimdi insülin tedavisine geçen hastaların sosyal ve kişisel gereksinimlerinin daha fazla etkilendiği belirlendi. Memur hastaların ve tedavi şekli insülin olanların daha fazla tedavi engeli ile karşılaştı̆g 1 tespit edildi. Okula gitmeyen ve düzenli olarak kontrollerini yaptırmayan hastaların daha fazla izleme engeli ile, diyabete bağl1 kronik komplikasyon gelişmiş hastaların ise daha fazla egzersiz engeli ile karşılaştıkları tespit edildi. Hastaların yaşları arttıkça negatif tutumlarının arttığı, hastalık süresi arttıkça daha çok kontrol problemi yaşadıkları ve sosyal ve kişisel gereksinimlerinin daha çok etkilendiği belirlendi.

Hastaların metabolik kontrol değişkenleri ortalamalarının oldukça yüksek düzeyde olduğu tespit edilmiştir. Hastaların $\mathrm{HbAlc}$ değerleri arttıkça izleme engellerinin arttığı, BKI arttıkça egzersiz engellerinin arttığı, HDL kolesterol düzeyi arttıkça kontrol problemlerinin ve LDL kolesterol düzey arttıkça da negatif tutumlarının arttığı belirlenmiştir. 
$\mathrm{Bu}$ sonuçlar doğrultusunda;

Hastaların diyabet yönetimi konusunda daha fazla desteklenmesi, hastaların olumsuz tutumlarının değiştirilmesi konusunda uygun girişimlerin yapılması, hastaların karşılaştıkları kontrol problemlerinin ve etkilenen sosyal ve kişisel gereksinimlerinin belirlenmesi ve engellerin ortadan kaldırılmasına yönelik girişimlerin planlanması, hastaların tedavi, izlem ve egzersiz ile ilgili karşılaştıkları engellerin çözümüne yönelik hastaların eğitimi ve desteklenmesi önerilmektedir. Özellikle diyabetli birey ve ailesine eğitim ve danışmanlık rolü bulunan diyabet hemşirelerinin, karşılaştıkları Tip 2 diyabet hastalarının sosyodemografik ve hastalık özelliklerini göz önünde bulundurarak, diyabet kontrolünü zorlaştıran faktörlere yönelik girişimlerde bulunmaları, eğitim programları düzenlemeleri diyabet yönetimine katkı sağlayabilir.

\section{Kaynaklar}

1. World Healty Organization. Global report on diabetes 2016 (11 Aralık 2016). Erişim adresi: http://apps.who.int/iris/bitstream/10665/2048 71/1/9789241565257_eng.pdf?u.

2. International Diabetes Federation. IDF Diabetes Atlas 2015 (22 Mayıs 2017). Erişim adresi:

http://www.diabetesatlas.org/resources/2015atlas.html.

3. Sağlık Bakanlığı Türkiye Halk Sağlığ Kurumu. 2015-2020 Türkiye Diyabet Programı. 2.Bask1, 2014.

4. Erdoğan S. Diyabet Eğitimi ve Danışmanlık. Diyabet Hemşireliği Derneği (10 Mayıs 2017).

http://www.tdhd.org/dhd_kitap/15blm.pdf.

5. Heinrich E, Schaper NC, Vries NK. Selfmanagement interventions for type 2 diabetes: a systematic review. European Diabetes Nursing. 2010;7(2):71-76.

6. Satman İ, İmamoğlu Ş, Yilmaz C, Akalin S, Salman S, Dİnççağ N. Diabetes mellitus ve komplikasyonlarinin tanı, tedavi ve izlem kılavuzu. Ankara: Türkiye Endokrinoloji ve Metabolizma Derneği; 2016.

7. Fitzgerald JT, Davis WK, Connell CM, Hess GE, Funnell MM, Hiss RG. Development and validation of the Diabetes Care Profile. Evaluation \& the health professions. 1996;19(2):208-230.
8. Kahraman G, Tavşanlı NG, Baydur H, Özmen D, Özmen E. Validity and reliability of The Diabetes Obstacles Questionnaire in type-2 diabetic patients. Anatolian Journal of Psychiatry. 2016;17:33-44.

9. Kaplan Y, Kurt S, Ünaldı HK, Erkorkmaz Ü. Diyabetik polinöropati için risk faktörleri. Archives of Neuropsychiatry. 2014;51(1):1114.

10. Erol Ö. Hipoglisemi korkusu ve yönetiminde hemşirenin rolü. Turkiye Klinikleri Hemsirelik Bilimleri. 2012;4(1):37-44.

11. Özcan Ş. Diyabetli hastalarda hastalığa uyumu etkileyen faktörlerin değerlendirilmesi [Doktora tezi]. İstanbul: İstanbul Üniversitesi; 1999.

12. Önsüz MF, Topuzoğlu A. İstanbul ilinde çeşitli sağlik kuruluşlarında ayaktan izlenen tip 2 diyabetli hastalarda glisemİk kontrolün ve etkileyen faktörlerin değerlendirilmesi. Nobel Med. 2010;39:45-55.

13. Azak A, Altundağ S, Sert H. Tip 2 diabetes mellituslu hastalarda akut yorgunluk sendromu ve etkileyen faktörler (Acute fatigue syndrome and factors effecting it in patients with type 2 diabetes mellitus). Firat Üniversitesi Sağlık Bilimleri Tıp Dergisi. 2008;22:73-6.

14. Anderson RM, Donnelly MB, Gressard CP, Dedrick RF. Development of diabetes attitude scale for health-care professionals. Diabetes Care. 1989;12(2):120-127.

15. American Diabetes Association. Standards of medical care in diabetes-2017: summary of revisions. Diabetes Care. 2017;40:4-5.

16. Kara K, Çınar S. Diyabet bakım profili ile metabolik kontrol değişkenleri arasındaki ilişki. Kafkas J Med Sci. 2011;1(2):57-63.

17. Samancioğlu BE, Karadağ A, Erkan E, Aktürk A, İlter M, Aktürk C. Tip 2 diyabetik hastalara verilen diyabet eğitiminin içeriği ve hastaların hastalı tutumu. İkçüsbfd. 2017;2(1):1-5.

18. Herath HM, Weerasinghe $\mathrm{N}$, Dias $\mathrm{H}$, Weerarathna T. Knowledge, attitude and practice related to diabetes mellitus among the general public in Galle district in Southern Sri Lanka: a pilot study. BMC public health. 2017;17(1):535-537

19. Al-Maskari F, El-Sadig M, Al-Kaabi JM, Afandi B, Nagelkerke N, Yeatts KB. 
Knowledge, attitude and practices of diabetic patients in the United Arab Emirates. PLoS One. 2013;8(1):1-8.

20. Al-Haddad M, Mi MI, Hassali M, Sulaiman SS, Maarup N. Social and psychological evaluations of diabetic patients towards disease management: A cross-sectional study at a university health center in malaysia. Journal of Clinical and Diagnostic Research. 2010;4:2798-2803.

21. Cunningham V, Mohler MJ, Wendel CS, Hoffman RM, Murata GH, Shah JH, et al. Reliability and validity of the DCP among hispanic veterans. Evaluation \& the health professions. 2005;28(4):447-463.

22. Li J, Li Z, Zhao W, Pan H, Halloran EJ. The reliability and validity of the Diabetes Care Profile for Chinese populations. Evaluation \& the health professions. 2015;38(2):200-218.

23. Orhan B, Gülseven Karabacak B. Tip 2 diyabetlilerde diyabete ilişkin bilişsel ve sosyal faktörler ve metabolik kontrol parametreleri arasındaki ilişki. Clin Exp Health Sc. 2016;6:1-8.

24. Korkmaz A, Korkut G. Türkiye'de kadının İşücüne katılımının belirleyicileri. Süleyman Demirel Üniversitesi İktisadi ve İdari Bilimler Fakültesi Dergisi. 2012;17(2):41-65.

25. Kartal A, Çağırgan $\mathrm{G}$, Tığglı H, Güngör $\mathrm{Y}$, Karakuş N, Gelen M. Tip 2 diyabetli hastaların bakım ve tedaviye yönelik tutumları ve tutumu etkileyen faktörler. TAF Prev Med Bull. 2008;7(3):223-230.

26. Fatema K, Hossain S, Natasha K, Chowdhury HA, Akter J, Khan T, et al. Knowledge attitude and practice regarding diabetes mellitus among Nondiabetic and diabetic study participants in Bangladesh. BMC public health. 2017;17(1):364.

27. Choi G, Jang SM, Nam HW. Current status of self-management and barriers in elderly diabetic patient. Korean Diabetes Journal. 2008;32(3):280-289.

28. Türkiye İstatistik Kurumu. Seçilmiş göstergelerle Van 2013 (27 Nisan 2018). Erişim adresi: http://www.tuik.gov.tr/ilGostergeleri/iller/VA N.pdf

29. Lautenschlager L, Smith C. Low-income American Indians' perceptions of diabetes.
Journal of nutrition education and behavior. 2006;38(5):307-315.

30. Gönen MS, Yürümez A, Hersek Ö, Altunoğlu E, Rakıcı H, Scism-Bacon J at al. The risk of severe hypoglycemia in patients with type 2 diabetes mellitus starting insulin therapy with premixed insulin analogues taken twice daily: an observational study in turkish patients. Turk Jem. 2013; 17: 83-88

31. Gogas Y, Yazici D, Özcan S, Tarçın Ö, Deyneli O, Akalın S. Hastanede yatan hastalarda hiperglisemi sıklığı. Marmara Medical Journal. 2013; 26: 68-71.

32. Mumu SJ, Saleh F, Ara F, Haque MR, Ali L. Awareness regarding risk factors of type 2 diabetes among individuals attending a tertiary-care hospital in Bangladesh: a crosssectional study. BMC research notes. 2014;7(1):599.

33. Mansyur CL, Rustveld LO, Nash SG, JibajaWeiss ML. Social factors and barriers to selfcare adherence in Hispanic men and women with diabetes. Patient education and counseling. 2015;98(6):805-810.

34. Altuğ F, Yağci N, Kitiş A, Büker N, Cavlak U. Evde yaşayan yaşlılarda yaşam kalitesini etkileyen faktörlerin incelenmesi. Yaşlı Sorunları Araştırma Dergisi. 2009;2(1):48-60.

35. Sönmez Y, Uçku R, Kitay Ş, Korkut H, Sürücü S, Sezer M, et al. İzmir'de bir sağlık ocağ bölgesinde yaşayan 75 yaş ve üzeri bireylerde yaşam kalitesi ve etkileyen etmenler. Dokuz Eylül Üniversitesi Tip Fakültesi Dergisi. 2007;21(3):145-153.

36. Çıtıl R, Öztürk Y, Günay O. Kayseri il merkezinde bir sağlık ocağına başvuran diyabetik hastalarda metabolik kontrol durumu ve eşlik eden faktörler. Erciyes Tip Dergisi. 2010;32(2):111-122.

37. Kaplan Y, Kurt S, Ünald1, HK, Erkorkmaz Ü. Diyabetik polinöropati için risk faktörleri. Archives of Neuropsychiatry. 2014; 51: 1114.

38. Aydın H, Deyneli O, Yavuz D, Tarçın Ö, Akalın S. Does the frequency of the selfmonitoring of blood glucose influence glycemic control in type 2 diabetic patients. Marmara Medical Journal. 2005; 18: 13-16. 